\title{
Anti-human sperm monoclonal antibody HS-11: a potential marker to detect bovine sperm capacitation and acrosome reaction in vitro
}

\author{
R. Rajamahendran ${ }^{1}$, J. D. Ambrose ${ }^{1}$ and C. Y. G. Lee $^{2}$ \\ ${ }^{1}$ Department of Animal Science, The University of British Columbia, Vancouver, Canada V6T 1Z4; and \\ ${ }^{2}$ Andrology Laboratory, Department of Obstetrics and Gynaecology. The University of British Columbia, \\ Vancouver, Canada V6T 2B5
}

\begin{abstract}
The crossreactivity between bull spermatozoa and monoclonal antibodies initially raised against mouse spermatozoa and human spermatozoa was tested by indirect immunofluorescent assay. The three anti-human spermatozoa monoclonal antibodies examined (HSK-9, HS-11, HS-63) crossreacted with methanol-fixed bull spermatozoa, whereas the anti-mouse spermatozoa monoclonal antibodies (MS-4 and MS-7) did not. A separate experiment was conducted to determine the binding ability of HSK-9, HS-11 and HS-63 with live (fresh) bull spermatozoa incubated $\left(39^{\circ} \mathrm{C}\right.$ in $\mathrm{CO}_{2}$ incubator) in a capacitation medium (modified Tyrode's supplemented with $10 \mu \mathrm{g}$ heparin $\mathrm{ml}^{-1}$ ). The binding of the monoclonal antibodies to the intra-acrosomal antigens of live bull spermatozoa was determined at $0,2,4,6$ and $8 \mathrm{~h}$ of incubation. At the beginning of incubation, binding was minimal $(3.2 \pm 1.7 \%)$, but a much higher percentage of spermatozoa exhibited fluorescent staining after $2 \mathrm{~h}$. The maximal binding was observed after incubation for $8 \mathrm{~h}(72.0 \pm 8.2 \%)$. The third experiment was performed to determine binding of HS-11 to frozen-thawed spermatozoa and to test whether there was any variation among bulls in HS-11 binding to spermatozoa, and to assess whether such binding is an indication of sperm capacitation. Frozen-thawed semen samples from five bulls were assessed for antibody binding after 0,2 , 4 and $6 \mathrm{~h}$ of incubation. Maximal binding was observed at $4 \mathrm{~h}$. Lysophosphatidylcholine $\left(100 \mu \mathrm{g} \mathrm{ml}^{-1}\right)$ induced acrosome reaction assay was performed to assess sperm capacitation at various intervals. A positive correlation observed between the degree of HS-11 binding and that of lysophosphatidylcholine-induced acrosome reaction suggested that HS-11 binds with capacitated, but not with acrosome-reacted, spermatozoa. Significant variation was observed among bulls in binding of HS-11 to spermatozoa. Split samples of frozen semen from the five bulls were also used for fertilization in vitro to assess their ability to fertilize and initiate cleavage of bovine oocytes matured in vitro. A close correlation $(r=0.90$; $P<0.05)$ was observed between binding of HS- 11 at $4 \mathrm{~h}$ and the cleavage rate of oocytes. The percentage increase in lysophosphatidylcholine-induced acrosome reaction was also correlated with HS-11 binding at $4 \mathrm{~h}(r=0.81 ; P<0.10)$. These results suggest that HS-11 is a potential marker for assessing pre-fertilization and post-thaw membrane changes in bull spermatozoa.
\end{abstract}

\section{Introduction}

A simple and reliable laboratory test to predict the fertility of breeding bulls has long been required for the bovine artificial insemination industry. Unfortunately no such test is available and attempts to develop such a test have met with little success. Even though the basic semen characteristics such as concentration, motility, morphology and freezability are important parameters to be considered, they are of limited value in predicting fertility (Salisbury et al., 1978). More detailed analysis such as the ratio of live:dead spermatozoa and enzyme activity have also been studied (Graham and Pace, 1970;

Manuscript received 6 September 1993
Stewart $e$ al., 1972) but were found not to be reliable indices of fertility. Tests based on the ability of bovine spermatozoa to penetrate zona-free hamster eggs (Graham and Foote 1987a, b) in vitro and intact homologous oocytes (Marquant-Le Guienne et al., 1990) have been used and found to be useful in the prediction of fertility of dairy bulls. However, these tests are time consuming and involve complex procedures. Ax et al. (1985) reported that the ability of chondroitin sulfate to induce the acrosome reaction in bull spermatozoa in vitro corresponds to non-return rates of dairy bulls. Marks and Ax (1985) suggested that the differences in binding affinity of heparin to bull spermatozoa might be used for predicting the fertility of dairy bulls. 
Whitfield and Parkinson (1992) reported that there is a significant correlation between the fertility of bulls (based on 90-day non-return rate) and the ability of their spermatozoa to undergo acrosome reaction in response to heparin treatment. Even though the process of capacitation is still poorly understood, there is general agreement that only capacitated spermatozoa undergo acrosome reaction (Ohzu and Yanagimachi, 1982; Llanos and Meizel, 1983; Parrish et al., 1988). As capacitation is a prerequisite for the acrosome reaction, the relationship between capacitation rate and fertility should be investigated. Unfortunately, there is no direct method available for differentiating between capacitated and non-capacitated spermatozoa in vitro. Assessment of capacitation is based on subjective or indirect methods such as hyperactivated motility of spermatozoa, induction of acrosome reaction in response to fusogenic agents (Parrish et al., 1988; Guyader and Chupin, 1991), in vitro egg penetration assays (Wheeler and Seidel, 1987; Boatman et al., 1988), in vitro fertilization assays (Marquant-Le Guienne et al., 1990) and sperm-zona binding assays (Fazeli et al., 1993). Membrane modifications and migration of certain sperm surface antigens known to occur during capacitation have been demonstrated in laboratory animals by the use of fluorescent-labelled antibodies (Myles and Primakoff, 1984; Okabe et al., 1986). Fann and Lee (1992) found that certain monoclonal antibodies ( $\mathrm{mAbs}$ ) raised against mouse and human sperm antigens were useful for monitoring capacitation and acrosome reaction of mouse spermatozoa in vitro.

The above observations indicate that it may also be possible to identify capacitation or acrosome reaction changes by using anti-sperm mAbs in domestic animals. If an immunofluorescence based capacitation/acrosome reaction assay could be developed for bull spermatozoa, it would be a significant contribution, not only for prediction of bulls' fertility in vitro, but also for further understanding the process of sperm capacitation and acrosome reaction of bovine spermatozoa. The objectives of the present study were therefore (i) to determine whether $\mathrm{mAbs}$ raised against mouse and human spermatozoa crossreact with bull sperm antigens (ii) to investigate whether such $\mathrm{mAbs}$ bind to live bull spermatozoa in culture and (iii) to determine binding of the mAb HS-11 to frozen-thawed bull spermatozoa and to detect any variation among bulls in sperm-antibody binding, and to determine whether such binding is correlated with sperm capacitation.

A part of this material was presented in abstract form at the Annual Conference of the International Embryo Transfer Society at Baton Rouge, Louisiana, USA, 1993.

\section{Materials and Methods}

\section{Monoclonal antibodies}

The anti-mouse spermatozoa monoclonal antibodies (MS-4 and MS-7) and anti-human spermatozoa monoclonal antibodies (HS-11, HS-63 and HSK-9) raised in BALB/c mice were used in this study. The procedures for generation and characterization of monoclonal antibodies against sperm antigens were reported by Lee et al. (1982, 1984). The mAbs HS-11 and HS-63 were selected from more than $100 \mathrm{mAbs}$ generated against human spermatozoa in a single cell fusion experiment (Menge et al., 1987), while HSK-9 was generated in a separate cell fusion experiment. All antibodies were of the $\operatorname{IgG} 1$ subclass.

\section{Semen samples}

Semen samples were collected using an artificial vagina, from Holstein bulls transported to the laboratory at $37-39^{\circ} \mathrm{C}$ and processed within $1 \mathrm{~h}$ for Expts 1 and 2. Fresh semen samples pooled from three bulls were used in Expt 1. Single ejaculates of fresh semen from five bulls were used in Expt 2. For Expt 3, two successive ejaculates were pooled and frozen from each of five bulls: nos 158, 166, 230, 361 and 371. Split samples of frozen semen from each bull were used for the HS-11 binding assay and for in vitro fertilization. All semen samples were provided by the British Columbia Artificial Insemination Centre (Langley, BC).

\section{Experiment 1: crossreactivity of $m A$ abs to methanol-fixed bull spermatozoa}

In this experiment the anti-mouse and anti-human sperm $\mathrm{mAbs}$ were screened for their crossreactivity to methanol-fixed bull spermatozoa. Spermatozoa were washed free of seminal plasma in PBS ( $\mathrm{pH} 7.4$ ) and the concentration was adjusted to $10^{7}$ spermatozoa $\mathrm{ml}^{-1}$. Drops of spermatozoa in suspension were placed on multi-spot slides (Fisher Scientific Ltd, Ontario) and allowed to dry on a $37^{\circ} \mathrm{C}$ slide warmer. Slides were then immersed in $95-100 \%$ methanol for 10 min to ensure permeation of the cell membranes and fixation of spermatozoa to the glass surface. Each of the five antibodies (initial concentration $1 \mathrm{mg} \mathrm{ml}^{-1}$ ) was initially diluted 1 in 100 in PBS $+0.5 \%$ BSA. Twofold serial dilutions were then made, starting from $I$ in 1000 to $I$ in 128000 . Ten microlitres of the $\mathrm{mAb}$ at each concentration was applied to designated spots on the slides and incubated at $37^{\circ} \mathrm{C}$ for $30 \mathrm{~min}$ in a dark, humid chamber. An unrelated $m A b R P 215$, previously shown to be specific only to ovarian cancer cells (Lee et al., 1992) was used as the negative control. The slides were then washed and $10 \mu \mathrm{l}$ of the second antibody (fluorescein isothiocyanate (FITC)-labelled goat antimouse IgG plus IgM: Sigma, St Louis, MO) at a $I$ in 100 dilution was added for an additional incubation for $30 \mathrm{~min}$. Slides were observed under an epifluorescence microscope (Carl Zeiss). Antibody binding was indicated by a bright green fluorescence of the acrosome region of the spermatozoa. Detailed procedures of this indirect immunofluorescent assay have been published by Fichorova and Anderson (1991) and Fann and Lee (1992).

\section{Experiment 2: binding of $m A$ bs to live, fresh bull spermatozoa}

This experiment examined the ability of the mAbs (HSK-9, HS-11 and HS-63) to bind fresh live spermatozoa in culture and the time course in antibody binding (as judged by fluorescent staining) to bull spermatozoa. Semen was washed three times in modified Tyrode's (TALP) medium, pH $7.4(100 \mathrm{mmol} \mathrm{NaCl}$ $1^{-1}, 3.1 \mathrm{mmol} \mathrm{KCl} \mathrm{l}{ }^{-1}, 25.0 \mathrm{mmol} \mathrm{NaHCO}_{3} \mathrm{l}^{-1}, 0.3 \mathrm{mmol}$ $\mathrm{NaH}_{2} \mathrm{PO}_{4} \mathrm{I}^{-1}, 21.6$ mmol sodium lactate $\mathrm{l}^{-1}, 2.0 \mathrm{mmol} \mathrm{CaCl}$ $\mathrm{I}^{-1}, 0.4 \mathrm{mmol} \mathrm{MgCl} 1^{-1}, 10.0 \mathrm{mmol}$ Hepes $\mathrm{I}^{-1}, 1.0 \mathrm{mmol}$ 
sodium pyruvate $\mathrm{l}^{-1}, 6.0 \mathrm{mg}$ fatty-acid-free BSA $\mathrm{ml}^{-1}$, $50.0 \mu \mathrm{g}$ gentamicin $\mathrm{ml}^{-1}$; Parrish et al., 1988) and spermatozoa resuspended in heparin-TALP medium (H-TALP) supplemented with $10 \mu \mathrm{g}$ heparin sulfate $\mathrm{ml}^{-1}$ (Sigma). Spermatozoa $\left(5 \times 10^{6} \mathrm{ml}^{-1}\right)$ were incubated in $90 \mu \mathrm{l}$ drops of this capacitation medium covered with paraffin oil, in a 24-well culture dish (Nunc, Roskilde) and incubated at $39^{\circ} \mathrm{C}$ in a $\mathrm{CO}_{2}$ incubator. After incubation for 0,2, 4, 6 and $8 \mathrm{~h}, 10 \mu \mathrm{l}$ of each $\mathrm{mAb}$ at a $\mathrm{I}$ in 100 dilution (initial antibody concentration $1 \mathrm{mg}$ $\mathrm{ml}^{-1}$ ) was added to the corresponding droplet and incubated for $30 \mathrm{~min}$. At the end of each incubation period, the microdrop was aspirated and coated on a multi-spot slide. The rest of the procedure for indirect immunofluorescent assay was as described in Expt 1. FITC-labelled Pisum sativum agglutinin (PSA: Sigma) at 1 in 100 dilution was applied on two spots of each slide to serve as an indicator for acrosome status. PSA is a plant lectin known to bind to acrosomal contents (Cross et al., 1986; Mendoza et al., 1992) of mammalian spermatozoa. Heads of acrosome-intact spermatozoa show a bright fluorescent staining with PSA conjugated to FITC, whereas acrosomereacted spermatozoa show no staining (Cross and Meizel, 1989). Data from the five bulls were pooled to demonstrate the time-dependent increase of antibody binding.

\section{Experiment 3: relationship between HS-11 binding to frozen-thawed spermatozoa, induced acrosome reaction and cleavage in vitro}

The mAb HS-II was used in this experiment to determine its binding to frozen-thawed bull spermatozoa, to test whether there was variation in its binding rate to spermatozoa from different bulls, and to determine whether HS- 11 binding was indicative of sperm capacitation. Three $0.5 \mathrm{ml}$ semen straws were thawed $\left(37^{\circ} \mathrm{C}\right.$ for $\left.40 \mathrm{~s}\right)$ in a water bath. A motile population of spermatozoa obtained following a swim-up procedure (Parrish et al., 1986) in TALP medium was cultured in microdrops of H-TALP medium for $0,2,4$ and $6 \mathrm{~h}$. About $85 \%$ initial motility (after swim-up) was observed in the semen samples of all bulls. HS-II was added to the appropriate drop and incubated for $30 \mathrm{~min}$. Concentration of spermatozoa and incubation conditions were the same as in Expt 2. Semen samples of two or three bulls were used in each trial on a random basis until the semen sample of each bull had been replicated four times.

Egg yolk lysophosphatidylcholine (LPC: Sigma) induced acrosome reaction assay was performed twice on semen samples of each bull to test whether the percentage fluorescent staining of spermatozoa was indicative of capacitation. Only capacitated bovine spermatozoa would undergo acrosome reaction in response to LPC (Parrish et al., 1988). LPC was dissolved in sterile Milli-Q water and distributed $(200 \mu \mathrm{g}$ per vial) in $1.5 \mathrm{ml}$ plastic vials, lyophilized and then stored at $-80^{\circ} \mathrm{C}$ until use. Representative samples of spermatozoa cultured for $0,2,4$ and $6 \mathrm{~h}$ were treated with $100 \mu \mathrm{g} \mathrm{LPC} \mathrm{ml}^{-1}$ for $15 \mathrm{~min}$. Treated spermatozoa were then subjected to a dual staining procedure (Trypan Blue for viability and Giemsa for acrosome staining). The technique described by Sidhu et al. (1992) for detecting true acrosome reaction of the water buffalo spermatozoa was modified at two steps: (i) the staining time with Trypan Blue was reduced to $2 \mathrm{~min}$ (from 8-10 $\mathrm{min}$ ), and (ii) the Giemsa stock solution was diluted only three times to obtain a working solution of approximately $0.25 \%$. Live spermatozoa with modified (swollen, discontinuous or denuded) acrosome cap were considered acrosome reacted. A minimum of 100 live spermatozoa was counted from each sample at each of the four time intervals. The percentage increase in acrosome reaction between $\mathrm{Oh}$ and $4 \mathrm{~h}$ was chosen for comparisons to avoid the possible confounding effect by spermatozoa undergoing early capacitation and spontaneous acrosome reaction, independent of LPC treatment.

In addition, a split sample of frozen-thawed semen from each of the above bulls was used in in vitro fertilization (IVF) experiments, to determine whether there was a relationship between the degree of HS-11 binding with spermatozoa or the degree of induced acrosome reaction and the ability of spermatozoa to fertilize and initiate cleavage in homologous oocytes. Bovine cumulus-oocyte complexes aspirated from ovaries at slaughter were matured in vitro for $26 \mathrm{~h}$ in the presence of bovine granulosa cells, in Ham's F-IO medium (Gibco, Grand Island, NY) supplemented with 10\% oestrous cow serum $\left(39^{\circ} \mathrm{C} ; 5 \% \mathrm{CO}_{2}\right.$ in air; maximum humidity). Frozenthawed spermatozoa were washed and layered under $1 \mathrm{ml}$ each of TALP medium distributed in several tubes, for swim-up ( $1 \mathrm{~h}$ at $39^{\circ} \mathrm{C}$ in $5 \% \mathrm{CO}_{2}$ in air). The active populations of swim-up separated spermatozoa from the different tubes were pooled, pelleted by centrifugation at $250 \mathrm{~g}$ for $4 \mathrm{~min}$, resuspended in IVF-TALP medium (114.0 mmol NaCl l-1 $3.16 \mathrm{mmol} \mathrm{KCl}^{-1}$ $25.0 \mathrm{mmol} \mathrm{NaHCO}_{3} 1^{-1}, \quad 0.35 \mathrm{mmol} \mathrm{NaH}_{2} \mathrm{PO}_{4} 1^{-1}$, $10.0 \mathrm{mmol}$ sodium lactate $\mathrm{I}^{-1}, 2.0 \mathrm{mmol} \mathrm{CaCl}_{2} \mathrm{I}^{-1}, 0.5 \mathrm{mmol}$ $\mathrm{MgCl}_{2} \mathrm{l}^{-1}, 0.2 \mathrm{mmol}$ sodium pyruvate $\mathrm{l}^{-1}, 6.0 \mathrm{mg}$ fatty-acid free BSA ml-1,50.0 $\mu \mathrm{g}$ gentamicin $\mathrm{ml}^{-1}$ ), and the concentration was adjusted to $2 \times 10^{6} \mathrm{ml}^{-1}$ before use for IVF. Spermatozoa and oocytes matured in vitro were incubated together in $100 \mu \mathrm{l}$ drops of IVF-TALP for fertilization, in the presence of bovine oviductal epithelial cells, for $12 \mathrm{~h}$. Zygotes were washed and co-cultured with bovine oviduct epithelial cells in Ham's F-10 medium supplemented with 10\% fetal bovine serum. The detailed procedure of the IVF system used was published by Sivakumaran et al. (1991). Four replicate trials were conducted and a total of about 100 oocytes per bull was used. Zygotes reaching the two-cell stage or beyond by $72 \mathrm{~h}$ after insemination were counted and expressed as percentage cleaved.

\section{Statistical analysis}

Data on percentage binding of HS-11 to bull spermatozoa at $4 \mathrm{~h}$, percentage increase in LPC-induced acrosome reaction between $0 \mathrm{~h}$ and $4 \mathrm{~h}$, and the percentage cleavage of oocytes assessed at $72 \mathrm{~h}$, were analysed by analysis of variance (ANOVA) using the General Linear Model procedure of the Statistical Analysis System (SAS, 1986). When the bull effect was significant, mean separation procedure was performed using $t$ test. A correlation coefficient between HS-1I binding and cleavage rate in vitro was calculated and its significance tested. A linear regression equation was obtained with the data, and the best-fit line for the regression was drawn in a scatter plot. The significance of the slope was also tested by ANOVA. 


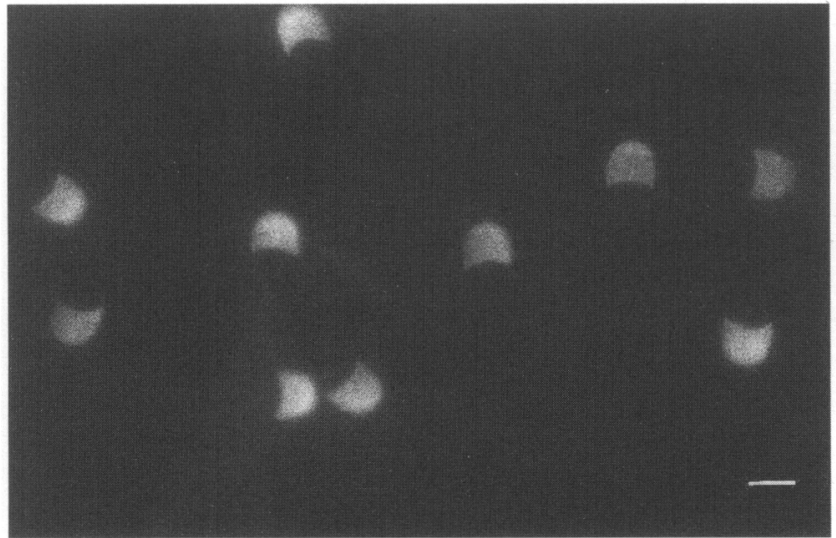

Fig. 1. Crossreactivity of the anti-human spermatozoa monoclonal antibody HS-11 to methanol-fixed bull spermatozoa demonstrated by an indirect immunofluorescent assay. Fresh bull spermatozoa were washed and coated on multi-well glass slides, fixed in methanol, washed and incubated with the mAb HS-11 for $30 \mathrm{~min}$. Fluorescein isothiocyanate (FITC)-labelled goat anti-mouse $\mathrm{IgG}+\mathrm{IgM}$ was used as the secondary antibody. Slides were then examined under a fluorescence microscope. Antibody binding was indicated by fluorescent staining of the acrosome region. Scale bar represents $4 \mu \mathrm{m}$.

Similarly, the correlation coefficient between HS-11 binding and percentage increase in induced acrosome reaction was also calculated and a regression line drawn.

\section{Results}

Experiment 1: crossreactivity of $m A$ Abs to methanol-fixed bull spermatozoa

Among the five $m A b s$ tested, the anti-mouse sperm antibodies (MS-4, MS-7) did not bind to methanol-fixed bull spermatozoa and were therefore considered as not crossreactive. However, all three anti-human spermatozoa mAbs (HSK-9, HS-11 and HS-63) bound to bull spermatozoa with detectable levels of fluorescent intensity at up to $I$ in 16000 dilution. The immunofluorescent staining pattern of methanolfixed bull spermatozoa incubated with HS-11 is shown (Fig. 1).

\section{Experiment 2: binding of $m A$ bs to live fresh bull spermatozoa}

When HSK-9, HS-11 and HS-63 were individually incubated with fresh spermatozoa in microdrops, they could all bind unfixed live spermatozoa. The binding trend with all three antibodies was similar. Pooled data from all five bulls showed that percentage binding (mean \pm SEM) at $\mathrm{O} h$ was minimal $(3.2 \pm 1.7)$. A progressive time-dependent increase was seen thereafter, until $8 \mathrm{~h}$ of incubation (Fig. 2; HS-11 binding only is shown). At $2 \mathrm{~h}$ after incubation, $31.0 \pm 10.8 \%$ spermatozoa were fluorescent stained, whereas maximum binding was observed after incubation for $8 \mathrm{~h}(72.0 \pm 8.2 \%)$. The FITC-PSA staining remained high $(>80 \%$ ) even at $4 \mathrm{~h}$ incubation, followed by a gradual decline.

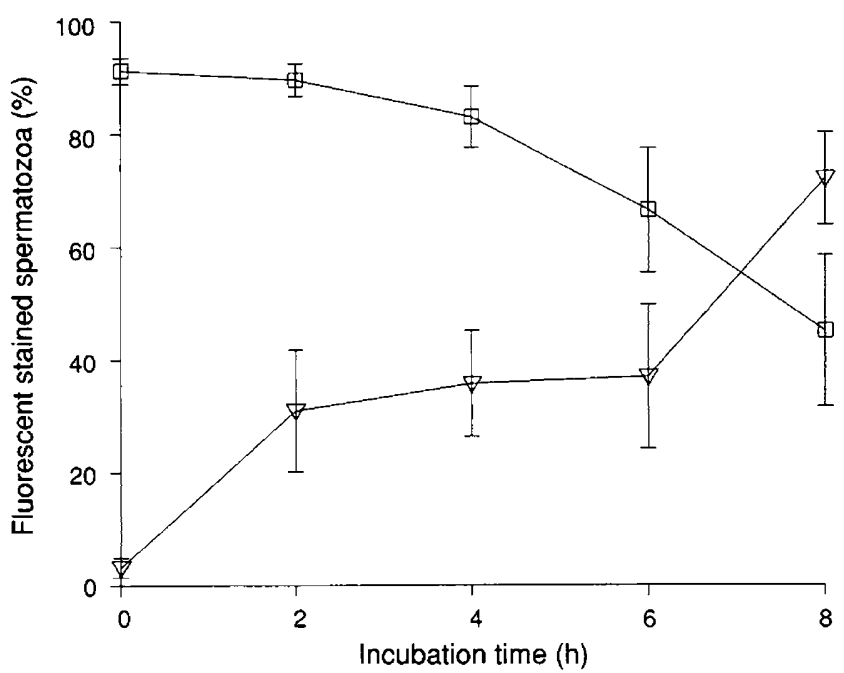

Fig. 2. Percentage binding (mean \pm SEM) of the mAb HS-11 $(\nabla)$ to unfrozen live bull spermatozoa (as determined by fluorescent staining) when they were co-incubated for $30 \mathrm{~min}$ at $0,2,4,6$ and $8 \mathrm{~h}$ in TALP medium supplemented with $10 \mu \mathrm{g}$ heparin $\mathrm{ml}^{-1}$. A time-dependent increase in the rate of binding from $\mathrm{Oh}$ to $8 \mathrm{~h}$ was evident. The acrosome status, as determined by fluorescein isothiocyanate (FITC)labelled Pisum satioum agglutinin (PSA) ( $\square$ ) binding, indicated that until $4 \mathrm{~h}$ most spermatozoa had intact acrosomes. From 4 to $8 \mathrm{~h}$, a gradual decrease in acrosome staining was observed, suggesting the onset of acrosome reaction ( $n=5$ bulls; data from the five bulls were pooled).

Experiment 3: relationship between HS-11 binding to live frozen-thawed bull spermatozoa, induced acrosome reaction and cleavage in vitro

The HS-11 binding trend to live frozen-thawed spermatozoa was different from that observed with fresh spermatozoa (Fig. 3a). At the start of the incubation, $20-40 \%$ of frozenthawed spermatozoa showed fluorescent staining. In contrast, fresh spermatozoa showed only $0-9 \%$ staining at the corresponding period. The degree of HS-11 binding to spermatozoa of two bulls 230 and 158 at $4 \mathrm{~h}$ was different $(P<0.05)$ from that of the other bulls 166,361 and 371 , with only about $20 \%$ spermatozoa showing fluorescent staining at $4 \mathrm{~h}$, compared with $>40 \%$ for the other bulls. There was no observable difference in motility and viability of spermatozoa among bulls (data not shown). The acrosomal status of spermatozoa at various periods as determined by PSA binding is presented (Fig. 3b).

There were differences $(P<0.05)$ among bulls in HS-1I binding and percentage increase in acrosome reaction after incubation for $4 \mathrm{~h}$ (Table 1 ). No significant differences $(P>0.10)$ were observed between bulls in the percentage cleavage following IVF. However, a positive correlation was observed $(r=0.90 ; P<0.05)$ between HS-11 binding to spermatozoa after incubation for $4 \mathrm{~h}$ and percentage cleavage in vitro (Fig. 4a). The slope was found to be significant $(P<0.02)$ and the SE of the estimate was 4.30. A positive correlation was also obtained between HS-11 binding and percentage change in LPC-induced acrosome reaction $(r=0.81$; 
(a)

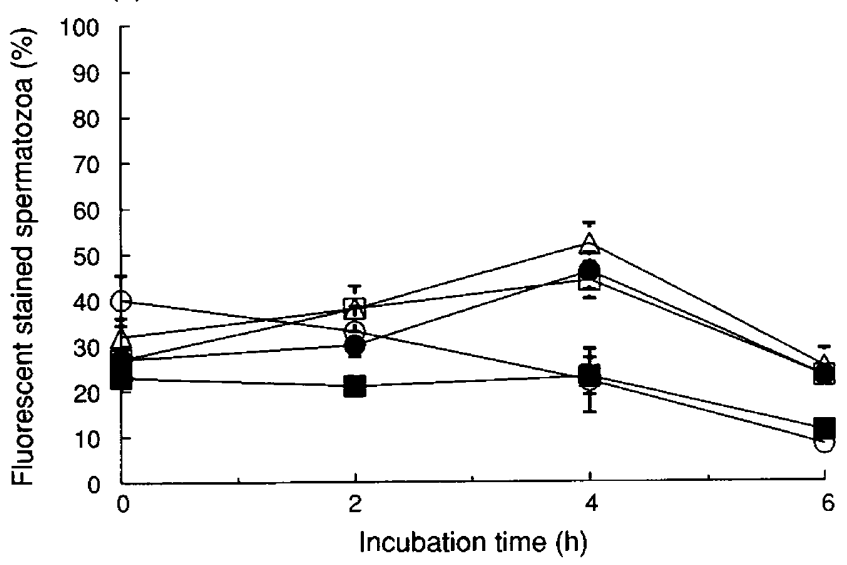

(b)

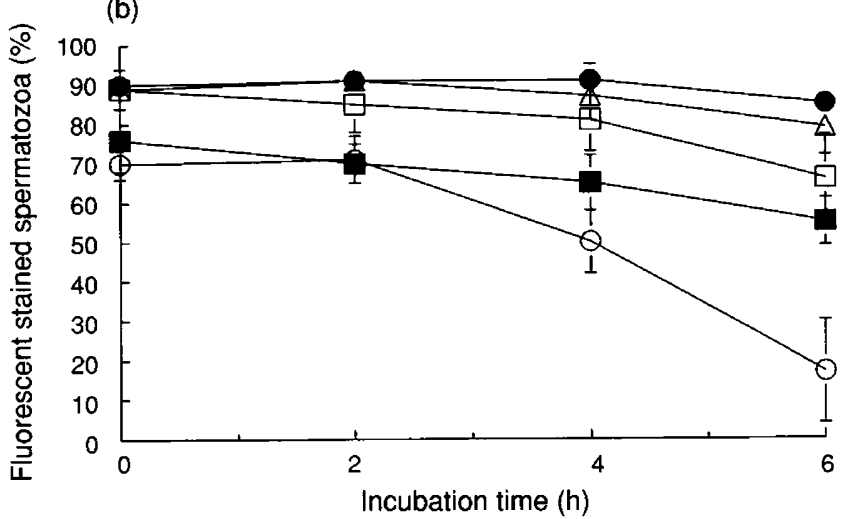

Fig. 3. (a) Time-dependent changes in HS-II binding (mean \pm SEM) to frozen-thawed bull spermatozoa at $0,2,4$ and $6 \mathrm{~h}$ incubation. Spermatozoa from five bulls (four replicates per bull) were incubated in capacitation medium from 0 to $6 \mathrm{~h}$. The mAb HS-11 and spermatozoa were co-incubated for $30 \mathrm{~min}$ each time. Maximum binding was observed at $4 \mathrm{~h}$. HS-11 binding to spermatozoa of bull 158 (D) and bull $230(O)$ were significantly different $(P<0.05)$ from the other bulls $166(\square), 361(\triangle)$ and $371(\bigcirc)$, even though motility and viability of spermatozoa remained almost the same for all bulls, at each time interval. (b) Acrosome status assessed by fluorescein isothiocyanate (FITC)-labelled Pisum sativum agglutinin (PSA). Sub-samples of frozen-thawed bull spermatozoa subjected to HS-11 binding were incubated with FITC-PSA. Fluorescent stained spermatozoa were indicative of an acrosome-intact status. With the exception of bull 230 (O), spermatozoa of all bulls (158 (口), I66 ( $\square$ ), $361(\triangle)$ and 371 (O)) exhibited a consistently high binding rate (mean \pm SEM) from 0 to $6 \mathrm{~h}$. Bull 230 showed a steady decrease in PSA binding, from $70 \%$ at $\mathrm{Oh}$ to about $20 \%$ at $6 \mathrm{~h}$.

$P<0.10$ ). The slope was significant $P<0.05$, and the $\mathrm{SE}$ of the estimate was 5.14 (Fig. $4 \mathrm{~b}$ ). It was generally observed that bull spermatozoa with low HS-1I binding at $4 \mathrm{~h}$ tended to undergo LPC-induced acrosome reaction at a lower rate. Similarly, their ability to fertilize and initiate cleavage in homologous oocytes was also low. However, spermatozoa with high HS-11 binding showed a relatively higher percentage of acrosome reaction, and a proportionately higher ability to initiate cleavage of bovine oocytes in vitro than did spermatozoa with low HS-11 binding.

\section{Discussion}

Crossreactivity was shown between the anti-human sperm $\mathrm{mAbs}$ and bull spermatozoa, indicating that there are conserved antigenic epitopes between these two species. Interspecies crossreactivity between mAbs directed against human sperm antigens and mammalian spermatozoa of several species was reported by Isahakia and Alexander (1984). The immunospecificity of HSK-9, HS-II and HS-63 to bull sperm antigens was tested and confirmed using various immunoassays (Ambrose et al., 1993a, b).

The percentage binding of these $\mathrm{mAbs}$ to fresh live bull spermatozoa was found to be time dependent. This observation suggests that the specific antigen/antigenic epitope(s) with which the antibodies bind probably become exposed in a time-dependent manner when incubated under capacitating conditions. At the beginning of incubation, the percentage of fluorescent stained frozen-thawed spermatozoa was much higher than that of fresh spermatozoa. This might be a result from damage to the sperm membrane during the freeze-thaw process. The damaged membrane(s) might have enabled the mAbs to readily enter and bind with their cognate intraacrosomal antigens. Alternatively, it is possible that up to $40 \%$ of frozen-thawed spermatozoa had undergone early capacitation. On the basis of a zona penetration assay, Wheeler and Seidel (1987) reported that frozen-thawed bull spermatozoa underwent capacitation at a much faster rate than did fresh spermatozoa. They proposed that the loss of sperm-bound phospholipids, combined with damage to the sperm membrane may induce rapid capacitation of frozen-thawed spermatozoa.

Significant differences were observed among bulls in terms of the percentage binding of HS-1I to spermatozoa at $4 \mathrm{~h}$, suggesting that the capacitation rate of spermatozoa may differ among bulls. Earlier studies showed that incubation of bull spermatozoa with $10 \mu \mathrm{g}$ heparin $\mathrm{ml}^{-1}$ for a minimum of $4 \mathrm{~h}$ promotes capacitation (Parrish et al., 1988). In the study reported here, a significant difference in antibody binding to spermatozoa was found among bulls at $4 \mathrm{~h}$ even though the motility and viability of spermatozoa were not different among bulls. It appears that spermatozoa of bulls 158 and 230 had an inherently low capacitation potential. A similar trend was also seen when their ability to fertilize and initiate cleavage of homologous oocytes was tested. By $6 \mathrm{~h}$, there was a decline in the HS-1I binding rate, suggesting that the incubated spermatozoa had started shedding the intra-acrosomal antigen, possibly owing to the initiation of spontaneous acrosome reaction. All the samples subjected to LPC treatment in this study showed a substantial increase in the initiation of acrosome reaction between 0 and $4 \mathrm{~h}$, suggesting that the maximal fluorescent staining observed at $4 \mathrm{~h}$ may be correlated with the degree of sperm capacitation changes. Previous reports indicated that there is a direct correlation between fertility rate and the ability of spermatozoa to undergo induced acrosome reaction in vitro ( $\mathrm{Ax}$ et al., 1985; Whitfield and Parkinson, 1992). Similarly, using the anti-human sperm mAb HS-II, a correlation was found in the study reported here between sperm capacitation (based on $\mathrm{mAb}$ binding) and fertility in vitro.

In the study reported here, PSA was used as an indicator for the assessment of acrosomal status. Despite a declining trend, 
Table 1. Percentage of bull spermatozoa positive for HS-11 binding after incubation for $4 \mathrm{~h}$, percentage increase in acrosome-reacted spermatozoa and percentage cleavage of bovine oocytes in the five bulls

\begin{tabular}{|c|c|c|c|c|c|}
\hline \multirow[b]{2}{*}{ Bull number } & \multirow{2}{*}{$\begin{array}{l}\text { Percentage of } \\
\text { spermatozoa } \\
\text { binding HS-11 } \\
\text { at } 4 \mathrm{~h}^{\mathrm{a}}\end{array}$} & \multirow{2}{*}{$\begin{array}{c}\text { Percentage increase } \\
\text { in acrosome-reacted } \\
\text { spermatozoa }{ }^{\text {ab }}\end{array}$} & \multicolumn{3}{|c|}{ Fertilization of bovine oocytes in vitro } \\
\hline & & & $\begin{array}{c}\text { Oocytes } \\
\text { tested }\end{array}$ & $\begin{array}{l}\text { Number } \\
\text { cleaved }\end{array}$ & $\begin{array}{c}\text { Cleavage } \\
(\%)^{\mathrm{a}}\end{array}$ \\
\hline 158 & $22.5 \pm 4.6^{c}$ & $22.5 \pm 0.4^{\mathrm{cd}}$ & 109 & 34 & $31.8 \pm 3.5^{c}$ \\
\hline 166 & $43.5 \pm 4.5^{\mathrm{d}}$ & $38.5 \pm 6.0^{\mathrm{c}}$ & 113 & 48 & $43.3 \pm 6.5^{c}$ \\
\hline 230 & $22.0 \pm 8.3^{c}$ & $16.0 \pm 2.0^{\mathrm{d}}$ & 97 & 39 & $37.3 \pm 6.6^{\mathrm{c}}$ \\
\hline 361 & $51.8 \pm 5.2^{\mathrm{d}}$ & $32.5 \pm 3.0^{c}$ & 101 & 64 & $58.3 \pm 6.5^{c}$ \\
\hline 371 & $46.0 \pm 4.5^{\mathrm{d}}$ & $28.0 \pm 8.0^{\mathrm{cd}}$ & 108 & 49 & $46.3 \pm 13.0^{c}$ \\
\hline
\end{tabular}

${ }^{a}$ Values are means $\pm \mathrm{SEM}$

bercentage increase in lysophosphatidylcholine-induced acrosome reaction, between $0 \mathrm{~h}$ and $4 \mathrm{~h}$ incubation.

${ }^{\mathrm{cd}}$ Means with different superscripts within the same column are significantly different $(P<0.05)$.

(a)

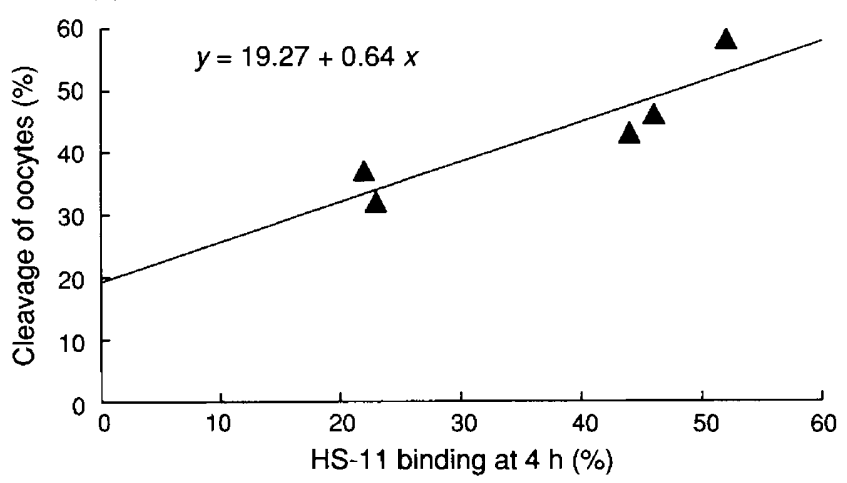

(b)

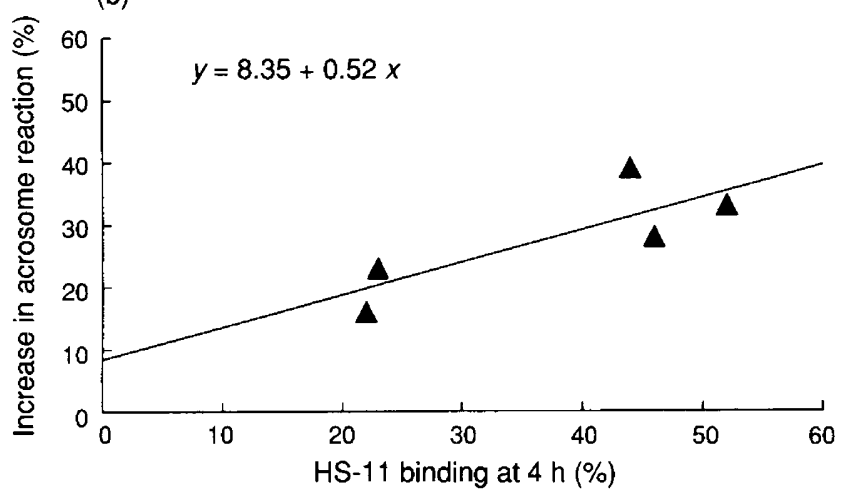

Fig. 4. (a) The anti-human sperm mAb HS-11 binding to spermatozoa of different bulls at $4 \mathrm{~h}$ incubation is compared with the ability of spermatozoa of the corresponding bull to fertilize and initiate cleavage of oocytes following IVF. The mean values of the four replicates of each bull pertaining to HS-11 binding and cleavage were used in the above scatter plot. The two measures were significantly correlated $(r=0.90 ; P<0.05)$. (b) The percentage HS-II binding to spermatozoa of different bulls after incubation for $4 \mathrm{~h}$ is compared with the percentage increase in acrosome reaction between $\mathrm{O} h$ and $4 \mathrm{~h}$, in response to treatment with $100 \mu \mathrm{g}$ lysophosphatidylcholine $\mathrm{ml}^{-1}$ for $15 \mathrm{~min}$. The mean values of two observations were used. The measures were significantly correlated $(r=0.81$; $P<0.10)$. even after $6 \mathrm{~h}$, PSA binding remained fairly high in most of the samples tested. It would be expected that there would be a proportionate decrease in PSA binding with the progression of the acrosome reaction. On acrosomal staining, it was found that even after incubation for $6 \mathrm{~h}$ and exposure to LPC, most of the live spermatozoa still had their acrosomal cap in place. However, acrosome swelling and discontinuity of membranes were evident in stained samples, suggesting that, even though the process of acrosome reaction is initiated early, shedding of the acrosomal cap is delayed. As disruption of the external membranes was evident, it is probable that portions of the acrosomal contents, including the antigens specific to HS-II, had begun to escape by this time, resulting in the lack of antigens for binding by HS-11. The remnants of the acrosomal contents probably still had sufficient glycoproteins to allow PSA binding, which could explain the high FITC-PSA staining, but low binding by HS-11 at $6 \mathrm{~h}$.

In conclusion, the crossreactivity between certain antihuman sperm $\mathrm{mAbs}$ and bull spermatozoa was demonstrated. Time-dependent changes were observed in HS-11 binding to frozen-thawed bull spermatozoa incubated under capacitation conditions, with maximum binding occurring at $4 \mathrm{~h}$, and a gradual loss of HS-II binding with the onset of acrosome reaction changes. A remarkable difference was observed in HS-11 binding between fresh and frozen-thawed live bull spermatozoa. There were distinct differences in $\mathrm{mAb}$ binding among bulls, and a close correlation was observed between HS-II binding at $4 \mathrm{~h}$ and the percentage cleavage of bovine oocytes. The present observations indicate that the anti-human sperm mAb HS-11 might be a potential marker for studying bull sperm-surface changes associated with capacitation and acrosome reaction, as well as in the assessment of freeze-thaw damage to bull spermatozoa. Further investigations are necessary to evaluate the usefulness of this anti-human sperm $\mathrm{mAb}$ as a marker for assessing pre-fertilization and post-thaw membrane changes in bull spermatozoa.

This study was funded by a Science Council of British Columbia Research Grant (No. 53/T-3) to R. Rajamahendran. The authors thank the British Columbia Artificial Insemination Centre, Langley, $\mathrm{BC}$, Canada, for supplying semen samples free of cost. The technical 
support of Selvalogini Kunanithy and Sivakumaran Kumarasingham is acknowledged. They thank Mohan Manikkam and Chris Taylor for their suggestions and help with statistical analyses.

\section{References}

Ambrose JD, Rajamahendran R and Lee CYG (1993a) Isolation and characterization of a bull sperm antigen recognized by a monoclonal human sperm antibody 15th Annual Winter Workshop of the Canada West Society for Reproductive Biology, Saskatoon Abstract 24

Ambrose JD, Rajamahendran R and Lee CYG (1993b) A conserved sperm acrosome antigen commonly recognized by three monoclonal antibodies Biology of Reproduction 48 (Supplement 1) Abstract 198

Ax RL, Dickson K and Lenz RW (1985) Induction of acrosome reactions by chondroitin sulfates in vitro corresponds to nonreturn rates of dairy bulls Journal of Dairy Science $68387-390$

Boatman DE, Andrews JC and Bavister BD (1988) A quantitative assay for capacitation: evaluation of multiple sperm penetration through the zona pellucida of salt-stored hamster eggs Gamete Research 19 19-29

Cross NL and Meizel S (1989) Methods for evaluating the acrosomal status of mammalian spermatozoa Biology of Reproduction 41 635-641

Cross NL, Morales P, Overstreet JW and Hanson FW (1986) Two simple methods for detecting acrosome reacted human spermatozoa Gamete Research 15 213-226

Fann CH and Lee CYG (1992) Monoclonal antibodies affecting sperm-zona binding and/or zona-induced acrosome reaction Journal of Reproductive Immunology 21 175-187

Fazeli AR, Steenweg W, Bevers MM, deLoos FAM, van der Broek J and Colebrander B (1993) Development of a sperm zona binding assay for bull semen Veterinary Record 132 14-16

Fichorova R and Anderson DJ (1991) Use of sperm viability and acrosomal status assays in combination with immunofluorescence technique to ascertain surface expression of spermatozoa antigens Joumal of Reproductive Immunology 20 1-13

Graham EF and Pace MM (1970) The release of glutamic oxaloacetic acid transaminase from spermatozoa as a test for assessing semen quality and fertility Biology of Reproduction 3 140-146

Graham JK and Foote RH (1987a) Dilauroylphosphatidylcholine liposome effects on the acrosome reaction and in vitro penetration of zona-free hamster eggs by bull spermatozoa: I. A fertility assay for fresh semen Gamete Research 16 133-145

Graham JK and Foote RH (1987b) Dilauroylphosphatidylcholine liposome effects on the acrosome reaction and in vitro penetration of zona-free hamster eggs by bull spermatozoa: II. A fertility assay for frozen thawed semen Gamete Research 16 147-158

Guyader C and Chupin D (1991) Capacitation of fresh bovine spermatozoa on bovine epithelial oviduct cell monolayers Theriogenology 36 505-512

Isahakia $\mathrm{M}$ and Alexander NJ (1984) Interspecies cross reactivity of monoclonal antibodies directed against human sperm antigens Biology of Reproduction 30 1015-1026

Lee CYG, Huang YS, Huang CH, Hu PC and Menge AC (1982) Monoclonal antibodies to human sperm antigens Joumal of Reproductive Immunology 4 173-181

Lee CYG, Wong E, Ritcher DE and Menge AC (1984) Monoclonal antibodies to human sperm antigens II Journal of Reproductive Immunology 6 227-238
Lee CYG, Chen KW, Sheu FS, Tsang A, Chao KC and Ng HT (1992) Studies of a tumor-associated antigen, COX- 1 , recognized by a monoclonal antibody Cancer Immunology Immunotherapy 35 19-26

Llanos MN and Meizel S (1983) Phospholipid methylation increases during capacitation of golden hamster spermatozoa in vitro Biology of Reproduction 28 1043-1051

Marks JL and Ax RL (1985) Relationship of non-return rates of dairy bulls to binding affinity of heparin to spermatozoa Journal of Dairy Science 68 2078-2082

Marquant-Le Guienne B, Humblot P, Thibier M and Thibault C (1990) Evaluation of bull semen fertility by homologous in vitro fertilization tests Reproduction Nutrition Development 30 259-266

Mendoza C, Carreras A, Moos J and Tesarik J (1992) Distinction between true acrosome reaction and degenerative acrosomal loss by a one-step staining method using Pisum sativum agglutinin Joumal of Reproduction and Fertility 95 $755-763$

Menge AC, Shoultz GK, Kelsey DE and Lee CYG (1987) Characterization of monoclonal antibodies against human sperm antigens by various immunoassays including sperm function assays and epitope evaluation American Joumal of Reproductive Immunology and Microbiology 13 108-114

Myles DG and Primakoff P (1984) Localized surface antigens of guinea pig spermatozoa migrate to new regions prior to fertilization Joumal of Cell Biology 99 1634-1641

Ohzu E and Yanagimachi R (1982) Acceleration of acrosome reaction in hamster spermatozoa by lysolecithin Journal of Experimental Zoology 224 259-263

Okabe M, Takada K, Adachi T, Kohama Y, Tsutomu M and Aonuma S (1986) Studies on sperm capacitation using monoclonal antibody - disappearance of an antigen from the anterior part of mouse spermatozoa head Joumal of Pharmacobio-Dynamics 9 55-60

Parrish JJ, Susko-Parrish JL, Leibfried-Rutledge ML, Critser ES, Eyestone WH and First NL (1986) Bovine in vitro fertilization with frozen-thawed semen Theriogenology 25 591-600

Parrish JJ, Susko-Parrish JL, Winer MA and First NL (1988) Capacitation of bovine spermatozoa by heparin Biology of Reproduction 38 1171-1180

Salisbury GW, VanDemark NL and Lodge JR (1978) Significance of semen quality. Physiology of Reproduction and Artificial Insemination of Cattle (2nd Edn) pp 428-441 Ed. GW Salisbury. WH Freeman and Co., San Francisco

SAS (1986) SAS Users' Guide. Statistical Analysis System Institute, Inc., Cary, $\mathrm{NC}$

Sidhu KS, Dhindsa JS and Guraya SS (1992) A simple staining procedure for detecting the true acrosome reaction in buffalo (Bubalus bubalis) spermatozoa Biotechnic and Histochemistry 67 35-39

Sivakumaran K, Rajamahendran R and Calder M (1991) The influence of reproductive status of cows at slaughter on oocyte number and maturation in vitro and the effect of co-culture systems on fertilization and subsequent development. Proceedings of the American Society of Animal Science 42 216-219

Stewart DL, O'Hagan C and Glover FA (1972) The prediction of fertility of bull semen from laboratory tests 7 th International Congress on Animal Reproduction and Artificial Insemination 2 1279-1283

Wheeler MB and Seidel GE, Jr (1987) Zona pellucida penetration assay for capacitation of bovine spermatozoa Gamete Research 18 237-250

Whitfield CH and Parkinson TJ (1992) Relationship between fertility of bovine semen and in vitro induction of acrosome reactions by heparin Theriogenology $3811-20$ 